\title{
Rethinking Teacher Retention In Hard-To-Staff Schools
}

Barbara Holmes, Winona State University, USA

DeJuanna Parker, Winona State University, USA

Jamel Gibson, Winona State University, USA

\begin{abstract}
National, state, and local educational agencies identify teacher retention as an issue of continuous importance and concern. This report addresses the issue of teacher retention through the lens of administrative effectiveness and involvement, as well as teachers' intrinsic motivations. Relevant findings include structural framing of the educational environment, student behaviors, school district demands for improvement, and teacher perspectives on administrative support. The report iterates that teacher retention does not have a one-size-fits-all solution, and that each school division and individual school must work purposefully to devise plans to retain its most effective teachers.
\end{abstract}

Keywords: Teacher Retention; Administrative Support; Organizational Change; Learning Outcomes

\section{INTRODUCTION}

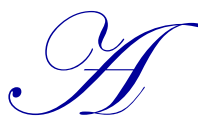
recent TNTP Report entitled The Irreplaceable: Understanding the Real Retention Crisis in America's Urban Schools (Jacob, Vidyarthi, \& Carroll, 2012) concluded that the "pervasive neglect of the nation's best teachers is a disgrace that derails school improvement efforts and robs millions of students of a potentially life changing education" (p. 4). Teacher retention is particularly acute in hard to staff schools. While teacher recruitment is a recognized problem facing school districts, teacher retention poses an even greater threat to successful student outcomes.

Ferlazzo (2015) suggests that teachers do not leave hard to staff schools; they are simply exiled. Teachers are exiled by fractious decision-making systems, lack of support by school leaders and by policy priorities that do not focus on student learning and developing professional learning communities. It is also postulated that good teachers leave because no one asks them to stay. Teachers also leave because of lack of respect. Riggs (2013) reported that teachers leave schools due to pervasive disrespect and the inability to influence academic decisions.

Researchers now focus on exploring administrative roles, especially that of the principal, in addressing the critical issue of teacher retention and attrition. In searching the extant body of literature from national, state, and local settings, Charlotte Advocates for Education (2004) studied teacher retention issues for several years and reported that poor working conditions is consistently cited factors contributing to teachers' decisions to remain or leave a school. Surveyed teachers indicated that principal leadership was critical in creating sustainable positive school environments. Rather than leave bad schools, teachers leave bad principals (Property of Charlotte Advocates for Education, 2004).

The Reform Support Network (2015), under the sponsorship of the U.S. Department of Education advocates using teacher retention efforts as part of principals' evaluation protocol. The report concludes that as principal evaluation systems undergo redesign, state boards of education should guide principals to focus on specific retention strategies by including retention as one of multiple measures of principal effectiveness.

\section{Why Teachers Leave}

Teachers leave challenging schools for a myriad of reasons. Allensworth, Ponisciak and Mazzeo (2009) suggested that teachers who leave underperforming schools do so because of the lack of principal effectiveness, weak administrative structures, student behaviors, uncompromising district practices, and poor compensation rates. As a 
result of the high teacher turnover rate, schools struggle to make academic gains, and build stable school cultures. Glazer (2013) concluded, "We're not doing a bad job at retaining teachers. We're doing an abysmal job."

\section{Weak Structures}

Eaker and DuFour (2015) and Freeman (2011) agreed that strong structures are essential to the success and forward movement of schools. These structures should be identifiable by all teachers while providing shape and direction for the future. Bolman and Deal (2008) proposed that obtaining prior knowledge helps leaders create solid foundations for teachers to build on as the school year progresses. When formulated structures in challenging schools are weak, staff members become unstable, parents worrisome, and the onus on student achievement diminishes and is drowned out by chaotic occurrences. Establishing structures by gaining prior knowledge is a necessary step in helping principals retain teachers and avoid repetitious mistakes from previous administration (Bryson, Anderson, \& Alston, 2011). Once principals understand how teacher viewpoints are developed, they are in a better position move the institution forward (Boston Consulting Group, 2014).

\section{Student Behavior}

Student behavior in schools with staffing challenges is a familiar factor that teachers confront (Gibson, 2015). Teachers often encounter student behaviors exhibited through acts of defiance, disruption of the classroom environment, use of inappropriate language and gestures, and engagement in confrontations, show of disrespect and insubordination, physical altercations, and even large-scale assault (Gibson, 2015). Hostile behavior exhibited by students comprise school culture and raise the stress levels of teachers throughout the day.

McCabe and Frede (2007) conclude that evidence exists of a rise in aggressive and challenging behaviors in the school setting and teachers are experiencing burnout at an alarming rate. As such, educators, school officials, and government officials express concern that demonstrated behaviors persist into adolescence and beyond. Addressing challenging students' behaviors minimizes teacher discomfort and non-compliant behavior during classroom instruction (McCabe \& Frede, 2007). Minimizing undesired student behaviors provides opportunities for students to gain better understanding and adds to teacher longevity within schools.

\section{District Practices}

Many school districts follow the same practices and mandates when it pertains to employing principals and teacher mobility. For example, typically, districts allow administrators at least three years to demonstrate effectiveness in bringing change to a school (Clark, Martorell, \& Rockoff, 2009), however, full demonstration of school improvement does not become established until approximately five years after implementation. School divisions are required to follow various mandates and practices, even in light of the fact that many districts have less experienced principals in hard-to-staff schools.

Mandates govern the organization's activities and implementation of protocols. (Bryson, Anderson, \& Alston, 2011). Mandates are divided into formal and informal categories. Formal mandates relate to recognizing and deciphering local, state, and federal laws. Informal mandates coincide with expectations regarding stakeholders and how various organizational rituals are conducted (Bryson, 2008). Understanding how district mandates operate assists in fostering understanding as to what is legally required and how the organization will be allowed to proceed (Bolman \& Deal, 2008; Bryson, 2008).

Clark, Martorell, and Rockoff (2009) noted that priority and focus schools are titles that schools acquire due to academic performance. Priority schools implement all seven turnaround principles using intervention strategies that are sufficient to achieve change and demonstrate progress. Focus schools currently do not meet the needs of students based on subgroup performance. Still, focus schools have a mandate to implement intervention strategies similar to other research-based mediations, as do priority schools. These titles and practices are rules and steps to which districts must adhere. However, the protocols may not be in the best interest of the school. 


\section{The Role of Teacher Self-Motivation in Retention}

As researchers analyze retention, key contributing factors emerge as influencers of teacher retention. Factors such as appreciation and support, environments that encourage collegial learning opportunities and school cultures where accomplished teaching can flourish and grow may be critical to extended teaching careers (Darling-Hammond, 2003; Huysman, 2007). School leadership is a central ingredient of the formula.

The school principal plays a major role in creating a professional atmosphere (Hughes, 2012). The principal is also instrumental concerning retention of qualified teachers through a range of actions, including providing teachers with support and a shared sense of governance, recognizing and rewarding teachers' accomplishments, supporting teacher professional development, and providing opportunities for sharing expert knowledge, professional learning outcomes, and collaboration (Hughes, 2012).

Increased administrative support for teachers has resulted consistently in lower levels of teacher attrition and migration (Boyd, Lankford, Loeb, \& Wyckoff, 2005; Tickle, 2008). Other influential administration-centered retention factors include fewer student discipline problems (Kersaint, Lewis, Potter, \& Meisels, 2007), increased levels of faculty selfefficacy (Ingersoll \& Perda, 2008), class size (Arnold, Newman, Gaddy, \& Dean, 2005; Monk, 2007), and a collegial atmosphere (Boyd, 2008; Brown, \& Wynn, 2009). These factors continue to be associated with high teacher morale and other factors that prove to be decisive as related to recruitment and retention success in a school district or individual school (Brown, \& Wynn, 2009).

Chinn (2007) explored and described factors that contribute to experienced secondary school teachers' decisions to remain in a school division, district, or school. The inquiry, based on a grounded theory approach, examined lived experiences of in-service teachers' and teacher perceptions of commitment through a school leadership lens, as well as staff development. and overall professional climate. Study findings yielded mixed results pertaining to factors that influence teachers to remain in the profession. The investigator claimed that passion for teaching was the primary intrinsic motivation for experienced teachers to stay in the profession, but external factors were more influential in regards to retention decisions. The study found that when school building administrators focused on authentic student success and were supportive of teachers' professional growth and development, teachers were more likely to stay at the school. Additionally, the study found that working in a culture and climate that promotes a positive attitude for teachers and students, and collaboration among the teachers were critical elements influencing teacher retention (Chinn, 2007).

Brown and Wynn (2009) conducted a qualitative study to explore conjoint strategic initiatives and elements principals use to influence teacher retention. The researchers conducted open-ended interviews with 12 principals who are leaders in school districts that are small and urban, and that have the lowest beginning teacher attrition and transfer rates based on 2 years of collected school district success data. Regarding support, the researchers noted that being a visible presence and advocate for teachers was the most important factor to demonstrate faculty support. Brown and Wynn (2009) also found that focus on growth and development as opposed to evaluation and punishment is a cornerstone of supportive leadership. Providing concrete support in terms of ensuring teachers had proper materials to teach effectively was also determined to be evidence of support (Brown \& Wynn, 2009).

In another examination of connections between administrative support and teacher retention, Kimball (2011) suggested that school leadership influences retention from a position of human capital management, with the ultimate goal being school improvement. Principals understood that "simply handing teachers the classroom keys and demanding accountability for student outcomes is counterproductive" to school improvement, and teacher performance and retention (p. 16). The study found that a well-defined system devoted to management of performance, which also includes formal setting of goals, facile access to support and mentoring, ongoing feedback, and recognition of accomplishments, as well as repercussions for poor performance were critical indicators of teachers' attitudes toward the nexus of leadership support and retention decisions.

Other researchers have found fewer instances of teacher attrition and migration in schools where more administrative support for teachers, fewer student discipline problems, and higher levels of faculty involvement in the decisionmaking process exist (Hofstetter, 2014; Huysman, 2007; Kearney, 2011). These administrative supports help to engage 
teachers in working to develop retention motivations, which further confirm the critical nature of purpose, mastery, and autonomy, as described in Pink (2011). This type of principal support is influential on teachers' intrinsic motivations to remain in the profession.

\section{Steps to Rethinking Teacher Retention}

School districts must take certain steps to ensure that more teachers are retained at hard- to-staff schools. First, if institutions begin to identify strengths, weaknesses, opportunities, threats and challenges, they could better understand how to address concerns. Bryson (2008) asserted that utilizing the SWOC/T analyses, strength, weaknesses, opportunities, and challenges and threats, could assist in moving the institution forward towards success.

Second, using the framing model can help schools and districts to keep teachers in place. The framing technique is a model of mental positioning utilizing ideas and assumptions that help facilitate understanding of programmatic and organizational occurrences (Bolman \& Deal, 2008). The act of mentally and operationally framing a given problem allows the leader to uncover patterns and devise interpretations, which can then be used to create organizional meaning that may assist in diagnosing elements that cause problems, making judgments, and suggesting means by which to resolve pertinent issues at hand (Achinstein \& Barrett, 2004).

Third, utilizing the technology of external assessments can also assist educational institutions in becoming better maintaining teachers in tough schools. It also allows organizations to effectively and cheaply stay in tuned with occurrences in the outside world that could eventually affect the personnel at the school (Bryson, 2011). Three steps are required in using the technology of external assessments. They include scanning the environment for current and key trends, ranking key trends in order of importance, and providing detailed reports that will be useful to the organization for the purposes of planning (Bryson, 2011).

Fernandez and Rainy (2006) asserted the cookie cutter approach to issues of retention do not affect desired results when managing change, as schools and districts can be vastly different, even within the same school division. Institutions can consider many possible pathways to success with the phenomenon. As a result, change leaders in school districts should jointly pay attention to internal and external factors in order to establish, define, and mold the the future of the organization (Bryson, 2011; Fernandez \& Rainy, 2006).

\section{SUMMARY}

Rethinking teacher retention in hard to staff schools is a necessary step that school districts should take to address teacher attrition and begin retaining teachers. Change must occur with solid leadership. Principals in low-achieving or high poverty, minority schools tend to have a greater impact on student outcomes than principals at less challenging schools. Clark, Martorell, and Rockoff (2009) agreed that teachers are the primary influencers regarding student learning and achievement, but principals play a vital role as supporters of teachers' professional growth, development, and ultimately, retention. A highly effective principal can increase student achievement by retaining effective teachers, which helps to ensure stability in the classroom. When this occurs, schools can raise standardized test scores as much as 10 percentile points in just one year (Clark, Martorell, \& Rockoff, 2009). Additionally, effective principals may influence teacher retention by addressing other student outcomes that closely affect teachers, such as making efforts to reduce suspension rates, and improving graduation rates.

\section{AUTHOR BIOGRAPHIES}

Barbara Holmes is a professor at Winona State University in Winona, Minnesota in the department of Leadership Education. Dr. Holmes has published numerous research articles, and has guided many doctoral students to completion of the earned Ph.D. Most recently, Dr. Holmes has spearheaded efforts to create an Ed.D. in Education program at Winona State University.

DeJuanna Parker is an academic advisor at Lord Fairfax Community College in Warrenton, Virginia, and an adjunct faculty member at Winona State University in the department of Leadership Education. Dr. Parker is also a frequent presenter at national and international education conferences. 
Jamel Gibson is a secondary education administrator. Dr. Gibson has published articles on the topic of male aggression in elementary schools and strategies to address the issue.

\section{REFERENCES}

Achinstein, B., \& Barrett, A. (2004). (Re) Framing Classroom Contexts: How NewTeachers and Mentors View Diverse Learners and Challenges of Practice. Teachers College Record, 106, 716-746.

Allensworth, E., Ponisciak, S., \& Mazzeo, C. (2009). The schools teachers leave: Teacher mobility in Chicago public schools. Consortium on Chicago School Research, 1-43.

Arnold, M., Newman, J., Gaddy, B., \& Dean, C. (2005). A look at the condition of rural education research: Setting a difference for future research. Journal of Research in Rural Education, 20(6). Retrieved from http://www.umaine.edu/jrre/206.pdf

Bolman, L. G., \& Deal, T. E. (2008). Reframing organizations artistry, choice, and leadership. Hoboken, New Jersey: Jossy-ass.

Boston Consulting Group (2014). Teachers know best: Teachers' views on professional development. Bill and Melinda Gates Foundation. Retrieved from http://k12education.gatesfoundation.org/wp-content/uploads/2015/04/GatesPDMarketResearch-Dec5.pdf

Boyd, D. (2008). Who leaves: Teacher attrition and student achievement. Cambridge, MA: National Bureau of Economic Research

Boyd, D., Lankford, H., Loeb, S., \& Wyckoff, J. (2005). Explaining the short careers of high-achieving teachers in schools with low performing students. American Economic Review, 95(2), 166-171

Brown, K. \& Wynn, K. (2009). Finding, supporting, and keeping: The role 122 of the principal in teacher retention issues. Leadership and Policy in Schools, 8, 37-63

Bryson, J. (2008). Strategic planning for public and nonprofit organizations. Jossey-Bass.

Bryson, J., Anderson, S., \& Alston, F. (2011). Implementing and sustaining your strategic plan. John Wiley and Sons.

Chinn, R. (2007). Voices of experience: Why do secondary school teachers choose to remain in a mid-Atlantic exurban school district. (Doctoral dissertation). UMI No. DP 18970

Clark, D., Martorell, P., \& Rockoff, J. (2009). School principals and school performance. Working paper 38. National Center for Analysis of Longitudinal Data in Education Research. Retrieved from http://www.centerforpubliceducation.org/principal-perspective

Darling-Hammond, L. (2003). Keeping good teachers: Why it matters, What leaders can do. Educational Leadership, 60, 6-13.

Dymnicki, A., Weissberg, R., \& Henry, D. (2011). Understanding how programs work to prevent overt aggressive behaviors: A meta analysis of mediators of elementary school-based programs. Journal Of School Violence, 315-337.

Eaker, R., \& DuFour, R. (2015). Getting started: Reculturing schools to become professional learning communities. Solution Tree Press.

Ferlazzo, L. (2015). Response: 'Teachers don't leave high-poverty urban districts; They are exiled'. Education Week Teacher. Retrieved from:

http://blogs.edweek.org/teachers/classroom_qa_with_larry_ferlazzo/2015/05/response_teachers_dont_leave_highpoverty_urban_districts_they_are_exiled.html

Fernandez, S., \& Rainey, H. (2006). Managing successful organizational change in the public sector. Public Administration Review. Retrieved from https://doi.org/10.1111/j.1540-6210.2006.00570.x

Freeman, V. (2011). Education leadership: Exploring personality styles: Disc "high I" and colors. Review of Higher Education \& Self-Learning, 3(11), 54-57.

Gibson, J. A. (2015). Elementary school male aggression: Teacher behavioral intervention strategies. Doctoral Dissertation, Hampton University.

Glazer, J. (2013, August). Classroom contemplations: Why teachers leave the classroom. State Impact: Florida. Retrieved from https://stateimpact.npr.org/florida/2013/08/15/classroom-contemplations-why-teachers-leave-the-classroom/

Hofstetter, K. A. (2014). Qualitative case study of novice teacher attrition, retention, and veteran teacher longevity in an urban school setting. (Doctoral dissertation). Northcentral University. Prescott Valley, AZ. UMI No. 3645594

Hughes, A. (2012). The relationship between principal support and teacher retention in hard-to-staff schools. (Doctoral dissertation). University of Montana. Missoula, MT. ScholarWorks at University of Montana.

Huysman, J. T. (2007). Rural teacher satisfaction: An analysis of beliefs and attitudes of rural teacher job satisfaction. (Unpublished dissertation, University of Central Florida. Orlando). Retrieved from: http://etd.fcla.edu/CF/CFE0001656/Huysman_John_T_200705_EdD.pdf

Jacob, A., Vidyarthi, E., \& Carroll, K. (2012). The irreplaceables: Understanding the real retention crisis in America's urban schools. TNTP. Retrieved from: http://ntp.org/assets/documents/TNTP_Irreplaceables_2012.pdf]

Kearney, D. P. (2011). Factors that influence effective veteran teachers' decisions to remain in high-poverty elementary schools. (Doctoral dissertation). North Carolina State University. Raleigh, NC. UMI No. 3497201

Kersaint, G., Lewis, J. Potter, R., \& Meisels, G. (2007). Why teachers leave: Factors that influence retention and resignation, Teaching and Teacher Education, 23(6), 775- 794. 
Kimball, S. (2011). Principals: Human capital managers at every school. Phi Delta Kappan, 92(7), 13-18. Retrieved from http://www.jstor.org/stable/25822832

McCabe, L., \& Frede, E. (2007). Challenging behaviors and the role of preschool education. National Institute for Early Education Research. Preschool Policy Brief, 16.

Monk, D. (2007). Recruiting and retaining high-quality teachers in rural areas. Future of Children, 17(1), 155-174.

Pink, D. H. (2011). Drive: The surprising truth about what motivates us. New York: Riverhead.

Property of Charlotte Advocates for Education (2004). Role of principal leadership in increasing teacher retention: Creating a supportive environment. Retrieved from:

http://www.educationjustice.org/assets/files/pdf/Resources/Policy/Teaching\%20and\%20Leadership/Role\%20of\%20pri ncipal\%20leadership\%20in\%20increasing\%20teacher\%20retention.pdf

Reform Support Network (2015, August). Incorporating retention of effective and highly effective teachers in principal evaluations. Retrieved from: https://www2.ed.gov/about/inits/ed/implementation-support-unit/techassist/incorporatingretention.pdf

Riggs, L. (2013). Why do teachers quit? And why do they stay? The Atlantic. Retrieved from: https://www.theatlantic.com/education/archive/2013/10/why-do-teachers-quit/280699/

Tickle, B. (2008). Public school teachers' perceptions of administrative support and its mediating effect on their job satisfaction and intent to stay in teaching (Unpublished Dissertation). Virginia Polytechnic Institute and State University: Blacksburg, VA.

Workman, T., \& Cleveland-Innes, M. M. (2012). Leadership, personal transformation and management. International Review of Research in Open and Distance Learning, 13(4), 313-322. 